\title{
An extended global Earth system data record on daily landscape freeze-thaw status determined from satellite passive microwave remote sensing
}

\author{
Youngwook Kim ${ }^{1}$, John S. Kimball ${ }^{1}$, Joseph Glassy ${ }^{2}$, and Jinyang Du ${ }^{1}$ \\ ${ }^{1}$ Numerical Terradynamic Simulation Group, College of Forestry \& Conservation, The University of Montana, \\ Missoula, MT 59812, USA \\ ${ }^{2}$ Lupine Logic, Inc., Missoula, MT 59802, USA \\ Correspondence to: Youngwook Kim (youngwook.kim@ntsg.umt.edu)
}

Received: 8 June 2016 - Discussion started: 22 July 2016

Revised: 23 December 2016 - Accepted: 13 January 2017 - Published: 16 February 2017

\begin{abstract}
The landscape freeze-thaw (FT) signal determined from satellite microwave brightness temperature $\left(T_{\mathrm{b}}\right)$ observations has been widely used to define frozen temperature controls on land surface water mobility and ecological processes. Calibrated $37 \mathrm{GHz} T_{\mathrm{b}}$ retrievals from the Scanning Multichannel Microwave Radiometer (SMMR), Special Sensor Microwave Imager (SSM/I), and SSM/I Sounder (SSMIS) were used to produce a consistent and continuous global daily data record of landscape FT status at $25 \mathrm{~km}$ grid cell resolution. The resulting FT Earth system data record (FT-ESDR) is derived from a refined classification algorithm and extends over a larger domain and longer period (1979-2014) than prior FT-ESDR releases. The global domain encompasses all land areas affected by seasonal frozen temperatures, including urban, snow- and ice-dominant and barren land, which were not represented by prior FT-ESDR versions. The FT retrieval is obtained using a modified seasonal threshold algorithm (MSTA) that classifies daily $T_{\mathrm{b}}$ variations in relation to grid-cell-wise FT thresholds calibrated using surface air temperature data from model reanalysis. The resulting FT record shows respective mean annual spatial classification accuracies of 90.3 and $84.3 \%$ for evening (PM) and morning (AM) overpass retrievals relative to global weather station measurements. Detailed data quality metrics are derived characterizing the effects of sub-grid-scale open water and terrain heterogeneity, as well as algorithm uncertainties on FT classification accuracy. The FT-ESDR results are also verified against other independent cryospheric data, including in situ lake and river ice phenology, and satellite observations of Greenland surface melt. The expanded FT-ESDR enables new investigations encompassing snow- and ice-dominant land areas, while the longer record and favorable accuracy allow for refined global change assessments that can better distinguish transient weather extremes, landscape phenological shifts, and climate anomalies from longer-term trends extending over multiple decades. The dataset is freely available online (doi:10.5067/MEASURES/CRYOSPHERE/nsidc-0477.003).
\end{abstract}

\section{Introduction}

The freeze-thaw (FT) signal detected from moderate frequency $(37 \mathrm{GHz})$ satellite microwave brightness temperature $\left(T_{\mathrm{b}}\right)$ observations is sensitive to changes in the relative abundance of liquid water at the land surface between frozen and non-frozen conditions. The FT metric defines the predominant landscape frozen or non-frozen status within a sensor footprint and is insensitive to potential degradation from solar illumination variations and atmosphere cloud/aerosol contamination effects. These properties enable consistent global coverage and daily monitoring from available satellite microwave sensors (Kim et al., 2011; Zhao et al., 2014). Global satellite microwave sensors have been operational since the mid-1970s, while similar $T_{\mathrm{b}}$ observations from overlapping sensor records have enabled the development of one of the longest satellite environmental data records, delineating global daily FT dynamics and associated climate 
trends over multiple decades (Kim et al., 2011). The FT Earth system data record (FT-ESDR) was developed to provide a consistent and continuous long-term daily global FT data record to support climate, ecological and hydrological applications. The initial FT-ESDR domain encompassed global vegetated land areas where seasonal frozen temperatures are estimated to be a significant constraint to annual vegetation growth (Kim et al., 2011). The FT retrieval is derived on a grid-cell-wise basis using a temporal change classification of similar daily $37 \mathrm{GHz} T_{\mathrm{b}}$ observations from Scanning Multichannel Microwave Radiometer (SMMR), Special Sensor Microwave Imager (SSM/I) and SSM/I Sounder (SSMIS) sensor series, in relation to frozen and non-frozen $T_{\mathrm{b}}$ reference states (Kim et al., 2012).

The FT-ESDR has been widely used to define frozen temperature constraints to ecological and hydrological processes, as well as for monitoring seasonal shifts in land surface energy partitioning where frozen temperatures are a significant part of the annual cycle (Mao et al., 2015; Zhang et al., 2014; Zhu et al., 2016). Previous FT-ESDR applications have included documenting widespread increases in the annual thaw cycle and a general reduction in frozen temperature constraints to vegetation growth over the Northern Hemisphere from regional climate warming (Kim et al., 2012; Wang et al., 2015), analyzing spring thaw- and frostrelated impacts on vegetation phenology and productivity (Buermann et al., 2013; Kim et al., 2014a, b), and defining a potential growing season climate indicator for the US National Climate Assessment (Kenney et al., 2014). The FTESDR has also been used to document FT-related impacts to surface hydrology, including evapotranspiration and the timing and extent of seasonal snowmelt (Zhang et al., 2011; Kim et al., 2015), and river ice phenology (Park et al., 2016b). The FT-ESDR-defined frozen season was also used to estimate permafrost extent and stability over the pan-Arctic (Park et al., 2016a).

In this investigation, we utilize calibrated daily (morning (AM) and evening (PM) overpass) $37 \mathrm{GHz} T_{\mathrm{b}}$ retrievals from SMMR, SSM/I and SSMIS sensor series to refine and extend the FT-ESDR. New FT-ESDR enhancements include a larger global domain encompassing all land areas affected by seasonally frozen temperatures, including vegetated, barren, urban, ice- and snow-cover-dominant, and open-waterdominant areas. We exploit SMMR and continuing SSM/I operations to develop a longer data record (1979-2014) than prior FT-ESDR releases (Kim et al., 2011) extending over a shorter 20-year record (1988-2010). A modified seasonal threshold algorithm (MSTA) is used to classify daily FT status in relation to a $T_{\mathrm{b}}$-based FT threshold calibrated annually for each grid cell using daily surface air temperature (SAT) records from global model reanalysis. The FT classification accuracy is evaluated using independent daily SAT measurements from the global weather station network. Annual quality assessment (QA) maps are derived using empirical models describing estimated global variations in FT classification accuracy due to climate and terrain heterogeneity, open water cover and model calibration uncertainty. The FT-ESDR performance is also evaluated using other cryosphere data records including in situ lake and river ice phenology observations and satellite-derived Greenland surface melt dynamics. The FT-ESDR methods, database description and performance assessment are provided in the following sections.

\section{Data and methods}

\subsection{Satellite microwave brightness temperature observations}

The Nimbus-7 SMMR Pathfinder dataset contains $T_{\mathrm{b}}$ retrievals from October 1978 to August 1987. The SSM/I and SSMIS sensor records are part of the Defense Meteorological Satellite Program (DMSP) platform series and provide continuous global, twice-daily $T_{\mathrm{b}}$ measurements from $\mathrm{Au}-$ gust 1987 to the present. The SMMR sensor obtained $T_{\mathrm{b}}$ retrievals at multiple frequencies $(6.6,10.7,18.0,21.0$, and $37.0 \mathrm{GHz}$ ), with vertical (V-) and horizontal (H-) polarization (pol). The SMMR $T_{\mathrm{b}}$ measurements were obtained at a constant $50.31^{\circ}$ incidence angle and noon, as well as midnight equatorial crossings (i.e., overpass times). The SSM/I and SSMIS sensors obtain V-and H-pol $T_{\mathrm{b}}$ measurements at $19.3,37.0$ and $85.5 \mathrm{GHz}$, and $22.2 \mathrm{GHz} T_{\mathrm{b}}$ measurements at V-pol only. The SSM/I and SSMIS instruments have a constant $53.1^{\circ}$ measurement incidence angle and approximate 06:00/18:00 equatorial crossings.

Calibrated, overlapping 37 (V-pol) GHz $T_{\mathrm{b}}$ data records used for classifying FT status were acquired from SMMR (Knowles et al., 2000), SSM/I and SSMIS (Armstrong et al., 1994) in a consistent $25 \mathrm{~km}$ grid cell resolution global Equal-Area Scalable Earth Grid (EASE-Grid) v1.0 projection format (Brodzik and Knowles, 2002). Missing $T_{\mathrm{b}}$ data composed approximately $34.3 \pm 24.3$ [inter-annual SD] $\%$ of frozen temperature-affected land areas on an annual basis for the 1979-2014 record. Missing $T_{\mathrm{b}}$ data attributed to orbital gaps between satellite overpasses, particularly for the midlatitudes, were filled on a grid-cell-wise basis by linear interpolation of temporally adjacent, successful $T_{\mathrm{b}}$ retrievals to generate spatially and temporally consistent daily (AM and PM overpass) $T_{\mathrm{b}}$ observations as inputs for the landscape FT classification following previously established methods (Kim et al., 2011). The SMMR record was matched to the SSM/I record using pixel-wise adjustment of the SMMR $T_{\mathrm{b}}$ record based on empirical analyses of overlapping SMMR and SSM/I $T_{\mathrm{b}}$ measurements for 1987 to ensure cross-sensor consistency (Kim et al., 2012). Large temporal $T_{\mathrm{b}}$ gaps in January and December 1987 and January 1988 were filled using empirical relationships developed from ERA-Interim (Dee et al., 2011) global model reanalysis SAT and satellite $T_{\mathrm{b}}$ data records. The resulting daily $T_{\mathrm{b}}$ record was used to construct the FT-ESDR over an extended 36-year period (1979-2014). 
For this investigation, the FT-ESDR defines the predominant frozen or non-frozen condition of the landscape and does not distinguish among individual vegetation, snow and soil FT elements within a grid cell (Kim et al., 2011, 2012). The satellite microwave $T_{\mathrm{b}}$ retrievals represent the mean emitted radiation from the integrated land surface within the grid cell. The $37 \mathrm{GHz} T_{\mathrm{b}}$ retrievals used in the FT-ESDR have relatively high atmospheric transmittance and are sensitive to land surface FT variations (Andre et al., 2015; Holmes et al., 2013), while the $\mathrm{V}$-pol $T_{\mathrm{b}}$ retrievals are also relatively less sensitive to soil moisture variation, snow and ice stratification, and scattering than the H-pol retrievals (Green et al., 2012; Holmes et al., 2009; Owe et al., 2008). The $37 \mathrm{GHz}$ $T_{\mathrm{b}}$ sensitivity to landscape FT variations from surface soil, snow cover and vegetation elements within the sensor footprint is related to a relatively shallower characteristic microwave emitting depth than lower frequency $T_{\mathrm{b}}$ retrievals (Green et al., 2012), while the $37 \mathrm{GHz}$ emitting depth is generally greater under drier surface conditions (Ulaby and Long, 2014). Higher moisture levels in soil and vegetation layers reduce the effective depth of microwave FT sensitivity, while lower microwave frequencies have generally greater depth of FT sensitivity (Watanabe et al., 2011).

\subsection{Global FT-ESDR domain}

We used $0.25^{\circ}$ resolution ERA-Interim daily minimum SAT $\left(\mathrm{SAT}_{\min }\right)$ estimates and a simple cold temperature constraint index (CCI) to define the global FT-ESDR domain as all land areas where seasonally frozen temperatures influence ecological processes and land surface water mobility (Kim et al., 2011). The ERA-Interim global reanalysis was selected for the FT-ESDR domain definition because it contains consistent atmospheric and surface analyses with similar spatial and temporal resolution as the satellite $T_{\mathrm{b}}$ records. The 36-year (1979-2014) $0.25^{\circ}$ ERA-Interim daily SAT min $_{\text {. }}$ global record was resampled to a $25 \mathrm{~km}$ global EASE-Grid format. The CCI (days year ${ }^{-1}$ ) was derived for each global EASE-Grid cell using a bioclimatic growing season index and $\mathrm{SAT}_{\text {min }}$ as developed in Kim et al. (2011). The CCI values were derived for each year of the 36-year ERAInterim record on a per grid cell basis and used to identify cells constrained by seasonal frozen temperatures. The FTESDR domain was defined where the CCI exceeded a minimum threshold ( 5 days year ${ }^{-1}$ ) from the 36 -year average CCI record following previously developed methods (Kim et al., 2011). The prior FT-ESDR global domain encompassed only vegetated land areas where seasonally frozen temperatures are a major constraint to annual vegetation growth; the domain excluded grid cells where the areal open water cover fraction exceeded $20 \%$ or was dominated by other nonvegetated land cover categories. The new FT-ESDR domain described in the current investigation is $41.5 \%(\sim 27$ million $\mathrm{km}^{2}$ ) larger than the prior record and encompasses all frozen temperature-affected land areas $\left(\mathrm{CCI}>5\right.$ day year $^{-1}$ ), including vegetated, urban, open water, snow-ice-dominant, and barren landscapes defined from a static global IGBP land cover classification (Friedl et al., 2010).

\subsection{Freeze-thaw algorithms}

A seasonal threshold algorithm (STA) was applied to classify daily FT state dynamics from SSM/I daily $37 \mathrm{GHz}$ (V-pol) $T_{\mathrm{b}}$ time series to construct the prior FT-ESDR release (Kim et al., 2011). The STA used a spatial and seasonal scale factor, $\Delta T_{\mathrm{b}}(x, t)$, defined for an observation acquired at location $(x)$ and time $(t)$ as

$\Delta T_{\mathrm{b} p}(x, t)=\frac{\left(T_{\mathrm{b} p}(x, t)-\operatorname{FrozRef}(x)\right)}{(\operatorname{ThawRef}(x)-\operatorname{FrozRef}(x))}$,

where $T_{\mathrm{b} p}(x, t)[\mathrm{K}]$ is the $T_{\mathrm{b}}$ retrieval acquired at location $(x)$, time $(t)$, and polarization $(p)$; FrozRef $(x)[\mathrm{K}]$ and Thaw $\operatorname{Ref}(x)[\mathrm{K}]$ define $T_{\mathrm{b}}$ retrievals under respective frozen and thawed landscape reference states. The STA threshold was derived annually on a grid-cell-wise basis using an empirical linear regression relationship between the satellite $\Delta T_{\mathrm{b}}(x, t)$ and daily SAT records from the National Centers for Environmental Prediction and National Center for Atmospheric Research reanalysis (Kanamitsu et al., 2002).

In the latest FT-ESDR version described in this paper, a new modified seasonal threshold algorithm (MSTA) is used to classify daily (AM and PM) FT status from similar calibrated $37 \mathrm{GHz}$ (V-pol) $T_{\mathrm{b}}$ time series from SMMR, SSM/I and SSMIS records. The MSTA is defined as

FT status $=\left\{\begin{array}{ll}\text { Non-frozen, } & \text { if } T_{\mathrm{b}}>\text { threshold } \\ \text { Frozen, } & \text { if } T_{\mathrm{b}} \leq \text { threshold }\end{array}\right.$,

where the MSTA FT threshold was defined annually for each grid cell using an empirical linear regression relationship between the satellite $T_{\mathrm{b}}$ retrievals and daily SAT estimates from the ERA-Interim global reanalysis. The ERA-Interim SAT record was selected for the MSTA calibration because the resulting FT record produced the best global accuracy performance relative to alternative reference states defined from other reanalysis datasets and satellite (MODIS) land surface temperature (LST) records (not shown). The annual grid-cell-wise FT thresholds were derived separately for the AM and PM overpass $T_{\mathrm{b}}$ retrievals using corresponding daily SAT minimum $\left(\mathrm{SAT}_{\min }\right)$ and maximum $\left(\mathrm{SAT}_{\max }\right)$ values. Larger weighting of SAT values closer to $0{ }^{\circ} \mathrm{C}$ was used in selecting the corresponding $T_{\mathrm{b}}$-based FT threshold for each grid cell; weighting of the SAT and $T_{\mathrm{b}}$ regression relationship was derived using a cosine function within a temperature range extending from -60.0 to $30.0^{\circ} \mathrm{C}$ and representing $99 \%$ of the SAT frequency distribution defined from the 36-year ERA-Interim SAT global climatology. The resulting AM and PM FT classifications were combined into a daily composite (CO) with four discrete classification levels, including frozen (AM and PM frozen), non-frozen (AM and 
PM non-frozen), transitional (AM frozen; PM thawed), and inverse-transitional (AM thawed; PM frozen) states.

The MSTA approach assumes that the large changes in microwave dielectric constant of the land surface that occur around the $0^{\circ} \mathrm{C}$ temperature threshold are associated with landscape FT transitions that dominate the corresponding satellite $37 \mathrm{GHz} T_{\mathrm{b}}$ seasonal dynamics, rather than other potential sources of $T_{\mathrm{b}}$ variability (Kim et al., 2011). An advantage of the MSTA over the previous STA approach (Kim et al., 2011) is that the $T_{\mathrm{b}}$ threshold selection does not depend on frozen and non-frozen reference states derived by averaging $T_{\mathrm{b}}$ measurements over respective winter and summer periods, and is less sensitive to $T_{\mathrm{b}}$ data gaps during these reference periods. The grid-cell-wise $T_{\mathrm{b}}$ thresholds and annual calibration used for the MSTA reduce the potential influence of spatial and temporal variations in climate and land surface conditions on FT classification accuracy, and promote greater consistency in global product performance over the long-term record. The daily SAT record used for the MSTA calibration approximates FT-related shifts in near-surface air temperatures using a fixed $0.0^{\circ} \mathrm{C}$ temperature threshold. In contrast, the $37 \mathrm{GHz} T_{\mathrm{b}}$ retrievals used to construct the FTESDR are sensitive to land surface dielectric variations stemming from FT-related shifts in surface soil, snow cover and vegetation elements within the sensor footprint. The SAT and $T_{\mathrm{b}}$ records represent different physical phenomena with different spatial and temporal characteristics; these factors may contribute uncertainty to the MSTA thresholds and classification accuracy, which are represented in the FT-ESDR accuracy quality assurance metrics (Sect. 2.4).

\subsection{FT classification agreement and quality assurance}

We used independent in situ daily $\mathrm{SAT}_{\min }$ and $\mathrm{SAT}_{\max }$ measurements from the global weather station network to assess the FT-ESDR classification agreement following previously developed methods (Kim et al., 2011, 2012). The WMO weather station daily SAT measurements were obtained from the National Climate Data Center (NCDC) Global Summary of the Day (National Weather Services, 1988). The Euclidian distance between each FT-ESDR EASE-Grid cell centroid and WMO station locations was computed to select a single representative station closest to the center of a grid cell when two or more stations were located within the same EASEGrid cell. Daily $\mathrm{SAT}_{\min }$ and $\mathrm{SAT}_{\max }$ records for the selected stations were used to define daily frozen $\left(T \leq 0^{\circ} \mathrm{C}\right)$ and nonfrozen $\left(T>0{ }^{\circ} \mathrm{C}\right)$ temperature conditions and compared with corresponding FT classification results from the overlying EASE-Grid cells and respective AM and PM overpass periods, assuming that the local timing of daily $\mathrm{SAT}_{\min }$ and SAT $_{\max }$ occurs near the satellite equatorial crossing times (Frolking et al., 1999; Kim et al., 2012). The FT classification agreement was assessed through grid-cell-to-point comparisons between WMO daily SAT measurements and overlying FT-ESDR results. Previous studies indicate close correspon- dence between the SAT and $37 \mathrm{GHz}$ (V-pol) FT dynamics (Kim et al., 2011, 2012), which characterize the FT state of the topmost surface layer within a $25 \mathrm{~km}$ satellite footprint, including bare soil, snow, and vegetation elements (Owe and Van De Griend, 2001). Approximately $4153 \pm 632$ [interannual SD] weather stations were selected for the 1979-2014 period. Differences between the SAT measurement-based FT value and the corresponding FT-ESDR estimate from the overlying grid cell were used to define the global daily FT spatial classification accuracy, expressed as a proportion (\%) of the number of stations and overlying FT-ESDR grid cells with identical FT classification results relative to the total WMO station cells represented within the FT-ESDR domain on an annual, monthly and daily basis.

The mean annual FT classification agreement between WMO station SAT observations and FT-ESDR classification values was evaluated according to the dominant land cover characteristics within a grid cell, sub-grid-scale terrain heterogeneity and open water body fraction within a grid cell, and other factors potentially influencing FT classification agreement. The MODIS (MCD12C1, collection 051) $5.6 \mathrm{~km}$, 17-class IGBP global land cover product for the 2001-2012 MODIS record (Friedl et al., 2010) was used to define dominant land cover categories within each $25 \mathrm{~km}$ resolution FTESDR grid cell using a majority approach (de Jong et al., 2013; Dendoncker et al., 2008). A $300 \mathrm{~m}$ water body map for the 2010 epoch (from 2008 to 2012) produced from the European Space Agency (Defourny et al., 2016) was used to derive fractional open water coverage $\left(F_{\mathrm{w}}, \%\right)$ within each $25 \mathrm{~km}$ FT-ESDR grid cell; the $F_{\mathrm{w}}$ map only defines static open water body cover and does not account for temporally dynamic variations in surface inundation. A $1 \mathrm{~km}$ resolution digital elevation model (DEM; Hasting et al., 1999) was used to derive an elevation gradient (m), defined as the spatial standard deviation (SD) of the elevation distribution within each $25 \mathrm{~km}$ FT-ESDR grid cell. Drop-in-bucket averaging of finer-resolution ( $300 \mathrm{~m}$ and $1 \mathrm{~km}$ ) pixels was used to resample to the $25 \mathrm{~km}$ resolution EASE-Grid format.

An FT-ESDR quality assurance (QA) map was determined on an annual basis from multivariate linear regression analysis of global annual FT classification agreement with WMO weather-station-based FT results and four independent geospatial variables. The independent variables used in the QA analysis for each grid cell included the $F_{\mathrm{W}}$, elevation gradient, mean annual duration of transitional FT conditions, and the correlation ( $r$ value) between weighted ERA-Interim reanalysis SAT and satellite $T_{\mathrm{b}}$ time series used to define the MSTA FT threshold. The resulting QA calculations defined the mean annual classification accuracy (\%) for each grid cell and year of record, and were linearly rescaled between low (0) and best (1) relative quality values to define a final dimensionless QA metric. Quality control (QC) flags were used to identify other potential factors affecting FT classification agreement, including grid cells and days with missing and interpolated $T_{\mathrm{b}}$ observations, precipitation events (Fer- 
raro et al., 1996), extensive open water bodies $\left(F_{\mathrm{W}}>0.2\right)$ or complex terrain (elevation gradient $>300 \mathrm{~m}$ ).

\subsection{Comparison of FT metrics with independent cryosphere data records}

Three FT metrics were derived from the daily CO FT classification series for each year of record, including frozen season (FS) duration, primary spring thaw date, and nonfrozen season (NFS) duration. The FS duration was defined from the daily FT-ESDR as the total number of frozen or transitional (AM frozen, PM non-frozen) days per year (September-August), which is similar to number of frost days reported by Peterson (2005). The primary spring thaw date was determined as the first day (DOY) when 12 out of 15 consecutive days from January through June were classified as non-frozen (Kim et al., 2012). The NFS was defined as the number of classified non-frozen days for a calendar year (January-December). The resulting FT metrics were compared against other independent cryospheric data records, including lake and river ice duration observations from the Global Lake and River Ice Phenology Database from 1979 to 2013 (Benson and Magnuson, 2000), reported annual ice breakup dates for the Tanana River in the interior of Alaska (Nenana Ice Classic, 2011), and the NASA MEaSUREs Greenland surface melt record (Mote, 2014). The annual duration of lake and river ice was determined for each observation location as the period between reported seasonal freezing and thawing, and compared with the collocated FTESDR-based FS estimates. The reported Tanana River ice breakup dates from 1979 to 2003 were compared against the FT-ESDR-derived mean primary spring thaw dates for the surrounding basin defined within the overlying $5 \times 5$ grid cell $\left(\sim 15625 \mathrm{~km}^{2}\right)$ window.

The Greenland surface melt record was available from 1979 to 2012 at the time of this investigation and was compared against corresponding FT-ESDR-derived annual NFS results. The Greenland melt record is derived using similar satellite $37 \mathrm{GHz} T_{\mathrm{b}}$ retrievals as the FT-ESDR, but the $T_{\mathrm{b}}$ retrievals are used with a microwave emission model to distinguish either surface melt or no surface melt categorical conditions for each $25 \mathrm{~km}$ grid cell (Mote, 2014). The seasonal progression in proportional area and annual variation of surface melt and FT-ESDR defined NFS conditions were compared over the Greenland ice sheet area indicated from the Land-Ocean-Coastline-Ice database (Knowles, 2004). The Greenland melt record provides a synergistic geospatial database for FT-ESDR assessment over northern snow- and ice-dominant land areas where in situ weather station networks are extremely sparse.

\section{Results}

\subsection{Global FT-ESDR domain and frozen season characteristics}

The resulting FT-ESDR domain represents $\sim 60.5 \%$ $\left(\sim 93\right.$ million $\left.\mathrm{km}^{2}\right)$ of the global land area, compared to $\sim 52.5 \%$ for prior FT-ESDR releases (Kim et al., 2011). The larger global domain is shown in Fig. 1 and encompasses vegetation-dominant grid cells, as well as urban, large water body $\left(F_{\mathrm{w}}<100 \%\right)$, complex terrain, permanent snow/ice cover and barren land areas excluded from prior FT-ESDR releases. The maps in Fig. 1 show the mean annual frozen season (FS; days) and FS temporal SD derived from the 36-year (1979-2014) FT-ESDR record. The FS duration is approximately $151 \pm 82$ [spatial SD] days and $201 \pm 167$ days for respective Northern Hemisphere (NH) and Southern Hemisphere (SH) domains. The FT-ESDR captures characteristic FS increases at higher elevations, including Tibetan Plateau, Andes and Rocky Mountain areas, though finer spatial-scale FT variations over complex terrain are less distinct due to the coarse $(25 \mathrm{~km})$-resolution $T_{\mathrm{b}}$ retrievals. The FT-ESDR also depicts characteristic FS increases at higher latitudes, with maximum FS durations over polar permanent ice and snow areas of Greenland and Antarctica. The FS is generally shorter along coastal margins relative to inland areas, consistent with more moderate maritime climate conditions in the coastal zone. Annual FS variability is generally greater along the zones of transition between major air masses and associated climate regimes. Higher FS variability is also evident for coastal grid cells and warmer climate zones, which may reflect greater FT classification uncertainty in these areas as indicated from the FT classification and quality assessments described below.

\subsection{FT classification assessment}

The mean annual FT spatial classification agreement over the global domain and 36-year record was $90.3 \pm 1.4$ [interannual SD] $\%$ and $84.3 \pm 1.7$ [inter-annual SD] \% for respective PM and AM overpasses (Fig. 2) as derived from daily grid-cell-to-point comparisons against in situ SAT measurement-based FT observations from $4153 \pm 632$ [interannual SD] global WMO weather stations. These results showed general improvement in mean annual classification accuracy of $0.6 \%$ (PM overpass) and $1.9 \%$ (AM overpass) over prior FT-ESDR versions for the same period (19792012) and vegetated domain covered by the initial product release (Kim et al., 2011). Areas with improved accuracy include Central Asia, northern and central Europe, and South America (not shown). The mean annual FT spatial classification agreement for 1987 and 1988 was lower than other years of record due to large temporal $T_{\mathrm{b}}$ gaps in December 1987 and January 1988 coinciding with the SMMR to SSM/I sensor transition period. The FT classification results show pos- 


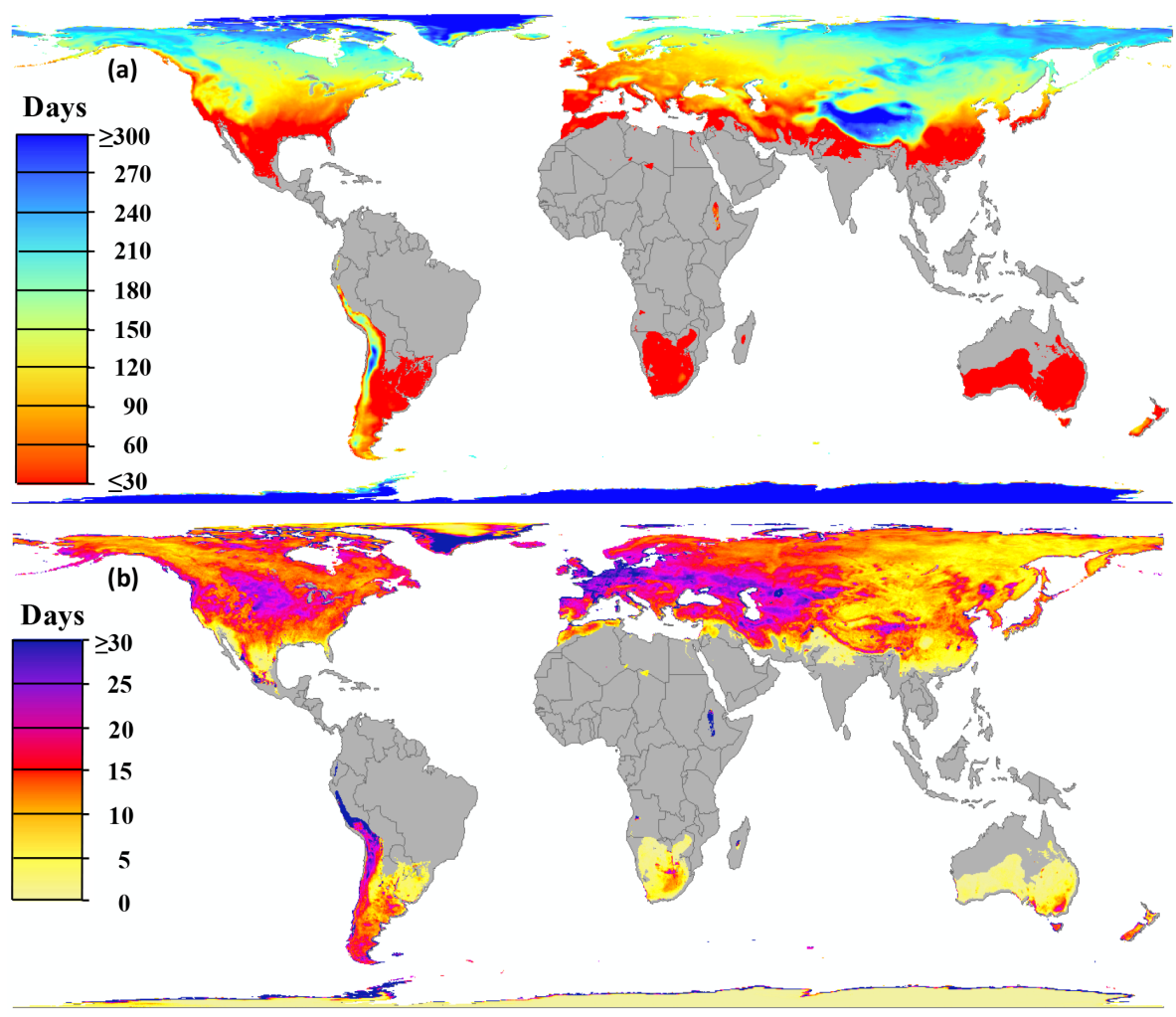

Figure 1. (a) Mean annual frozen season (frozen or transitional status) and (b) temporal standard deviation of the frozen season over the 36-year (1979-2014) record and global FT-ESDR domain; white and grey denote respective open water bodies and land areas outside of the FT-ESDR domain; grey areas depict grid cells where the mean cold temperature constraint index (CCI) was less than 5 days year ${ }^{-1}$ from the 36-year CCI record.

itive trends ( $p<0.001)$ toward increasing mean annual classification agreement of 1.4 and $1.1 \%$ decade $^{-1}$ for respective AM and PM overpasses over the 1979-2014 record. The increase FT accuracy coincides with a $0.3^{\circ} \mathrm{C}_{\text {decade }}{ }^{-1}$ mean SAT warming trend over the FT-ESDR domain and may be due to a corresponding decline in frozen conditions (Kim et al., 2012). The apparent FT accuracy trend may also reflect differences between SMMR and SSM/I portions of record, including variations in the location and number of weather stations used for validation and different overpass times between SMMR (noon/midnight) and SSM/I ( 06:00/18:00) $T_{\mathrm{b}}$ records. The lower FT classification agreement from the AM overpass $T_{\mathrm{b}}$ record is attributed to generally cooler diurnal temperature conditions and a corresponding larger number of daily FT variations over the annual cycle in the AM record relative to characteristic warmer midday temperature conditions and fewer FT variations in the PM results. Lower AM FT classification agreement may also be due to wetter surface conditions and temperature inversions during night-time diurnal SAT minimums (Owe and Van De Griend, 2001).

Monthly mean FT classification agreements for AM and PM overpasses and the 1979-2014 record are summarized

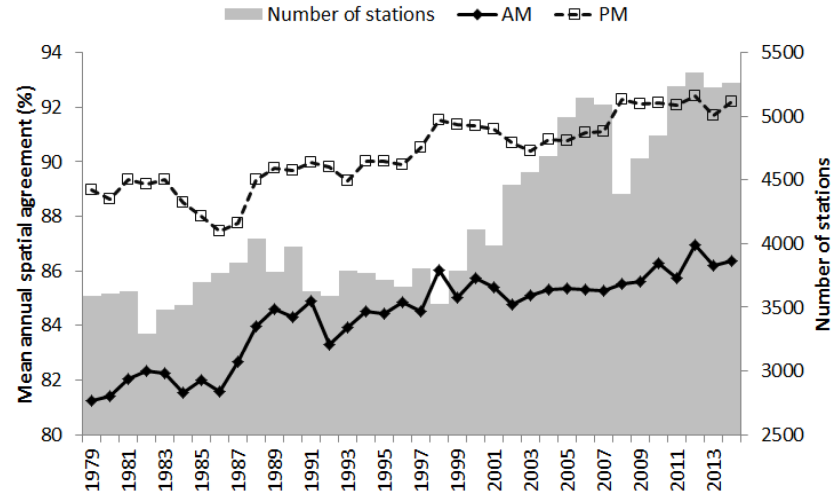

Figure 2. Mean annual FT spatial classification agreement (\%) between FT-ESDR results and corresponding daily SAT-based FT estimates from the global WMO weather station network. The FT classification agreement was determined on a daily basis for individual satellite AM and PM overpasses in relation to grid-cell-to-point comparisons with independent FT estimates derived from respective minimum and maximum daily SAT records. The bar graph denotes the number of global WMO stations used for FT assessment. 
Table 1. Mean monthly FT classification agreement (\%) for AM and PM overpasses in relation to WMO surface air temperature (SAT max and $\mathrm{SAT}_{\min }$ )-based FT metrics for Northern Hemisphere $(\mathrm{NH})$, Southern Hemisphere $(\mathrm{SH})$ and global domains. Values represent mean monthly spatial agreement (\%) and temporal standard deviation for the 1979-2014 record.

\begin{tabular}{lrrr|rrr}
\hline & \multicolumn{3}{c|}{ PM overpass } & \multicolumn{3}{c}{ AM overpass } \\
\cline { 2 - 7 } & $\mathrm{NH}$ & $\mathrm{SH}$ & Global & $\mathrm{NH}$ & $\mathrm{SH}$ & Global \\
\hline Jan & $81.0 \pm 1.9$ & $96.3 \pm 1.8$ & $81.9 \pm 2.0$ & $80.0 \pm 1.6$ & $95.8 \pm 2.0$ & $80.9 \pm 1.7$ \\
Feb & $81.9 \pm 1.8$ & $96.8 \pm 1.7$ & $82.7 \pm 1.9$ & $80.7 \pm 1.6$ & $96.5 \pm 1.5$ & $81.6 \pm 1.6$ \\
Mar & $84.3 \pm 2.5$ & $96.5 \pm 1.6$ & $84.9 \pm 2.5$ & $78.9 \pm 2.0$ & $95.4 \pm 1.1$ & $79.8 \pm 2.1$ \\
Apr & $91.6 \pm 1.8$ & $96.1 \pm 1.4$ & $91.9 \pm 1.9$ & $77.8 \pm 2.4$ & $92.5 \pm 2.1$ & $78.6 \pm 2.5$ \\
May & $96.0 \pm 0.9$ & $96.0 \pm 1.4$ & $96.0 \pm 1.0$ & $86.3 \pm 2.7$ & $87.0 \pm 2.8$ & $86.3 \pm 2.6$ \\
Jun & $97.6 \pm 0.7$ & $94.8 \pm 1.9$ & $97.5 \pm 0.7$ & $94.8 \pm 1.9$ & $80.1 \pm 3.9$ & $94.0 \pm 1.7$ \\
Jul & $98.1 \pm 0.5$ & $93.7 \pm 2.3$ & $97.9 \pm 0.5$ & $97.0 \pm 1.2$ & $77.2 \pm 3.0$ & $95.9 \pm 0.9$ \\
Aug & $97.5 \pm 0.6$ & $94.1 \pm 2.0$ & $97.3 \pm 0.6$ & $96.0 \pm 1.3$ & $80.6 \pm 2.9$ & $95.1 \pm 1.1$ \\
Sep & $96.1 \pm 0.8$ & $95.3 \pm 1.7$ & $96.1 \pm 0.8$ & $89.2 \pm 2.4$ & $86.2 \pm 2.9$ & $89.0 \pm 2.3$ \\
Oct & $91.4 \pm 1.9$ & $96.0 \pm 1.4$ & $91.6 \pm 1.9$ & $77.5 \pm 3.2$ & $91.1 \pm 1.6$ & $78.3 \pm 3.3$ \\
Nov & $83.5 \pm 2.7$ & $96.1 \pm 1.7$ & $84.2 \pm 2.8$ & $73.7 \pm 2.3$ & $93.5 \pm 1.5$ & $74.9 \pm 2.5$ \\
Dec & $80.2 \pm 1.9$ & $96.0 \pm 3.0$ & $81.1 \pm 2.0$ & $76.3 \pm 2.2$ & $94.7 \pm 1.7$ & $77.4 \pm 2.3$ \\
\hline
\end{tabular}

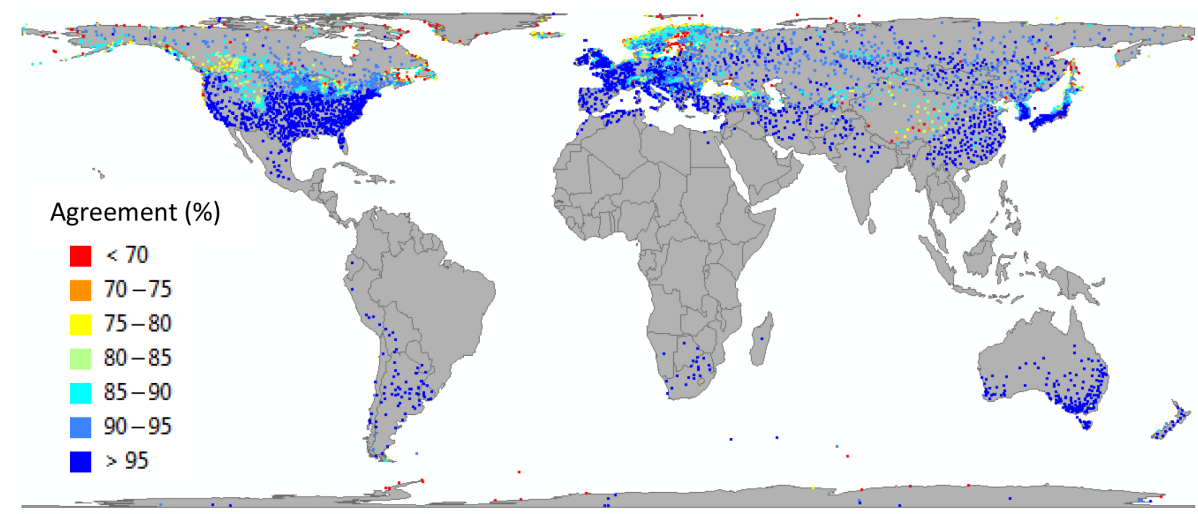

Figure 3. Spatial distribution of mean annual FT classification agreement (\%) for PM overpass results in relation to grid-cell-to-point

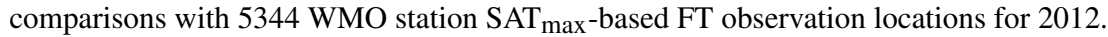

in Table 1 for the global domain and Northern Hemisphere $(\mathrm{NH})$, and Southern Hemisphere (SH) sub-regions. The FT classification agreement was assessed using daily SAT measurements from approximately $3912 \pm 556$ and $241 \pm 102$ respective NH and SH weather stations for the 1979-2014 record. The monthly pattern of mean FT classification agreement is generally lowest and highest for corresponding $\mathrm{NH}$ winter frozen and summer non-frozen seasons. Similarly, the monthly pattern for AM overpass FT results show larger agreement in summer relative to winter in the $\mathrm{SH}$, while the monthly agreement pattern for PM overpass results in the $\mathrm{SH}$ is more consistent throughout the year.

The mean annual FT spatial classification agreement from the PM overpass results in relation to 5344 global WMO stations for a selected year (2012) is $92.4 \pm 9.9$ [spatial SD] \% (Fig. 3). Lower latitude areas with characteristic warmer temperatures show generally greater mean annual FT classification agreement due to a longer non-frozen period. Relatively lower agreement occurs along coastal margins, and in mountainous regions. Sub-grid-scale heterogeneity in microwave dielectric properties and associated FT conditions within the coarse ( $25 \mathrm{~km}$ resolution) satellite footprint increase FT classification uncertainty along coastal margins (Howell et al., 2009; Kimball et al., 2001). In mountainous regions, complex terrain and microclimate variability promote heterogeneous frozen and non-frozen conditions within the coarser resolution satellite footprint, leading to greater FT classification uncertainty (Du et al., 2015). Arid climate areas with dry land surface conditions (e.g. Tibetan Plateau) have a deeper characteristic microwave emitting depth and larger volume scattering relative to areas with wetter surface conditions (Prigent et al., 2006; Han et al., 2015); these conditions may promote a lower FT signal-to-noise ratio and lower classification agreement with WMO SAT measurements (Grody and Basist, 1996; Han et al., 2015). 


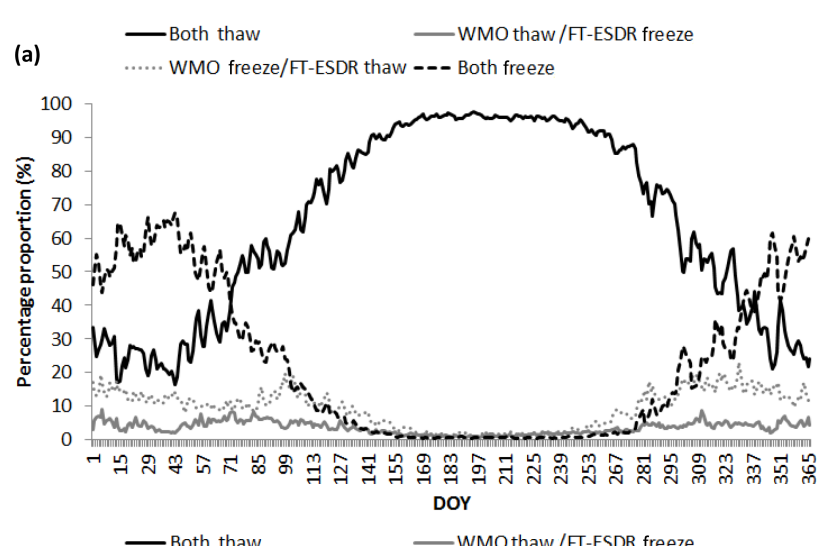

tent with previous studies (Derksen et al., 2005; Du et al., 2015; Lemmetyinen et al., 2011); however, the FT-ESDR results still show favorable agreement for water-affected grid cells despite expected larger constraints from $T_{\mathrm{b}}$ noise effects due to surface dielectric variations and microwave scattering over open water bodies. Permanent snow- and ice-dominant grid cells also show generally lower FT agreement than the other land cover classes, which may be due to variable surface scattering effects on $37 \mathrm{GHz}$ microwave emissions over snow and ice (Chang et al., 1990; Matzler, 1994); the apparent FT classification accuracy is still favorable in these areas but is based on relatively sparse WMO station observations. For most land cover classes, the PM FT classification agreement is generally greater than the AM overpass results except for snow- and ice-dominant grid cells where the AM FT classification agreement is approximately $2 \%$ greater than the PM overpass results; the greater apparent AM accuracy is attributed to a lower number of FT variations for AM than PM overpasses over relatively cold snow- and ice-dominant land areas throughout the year.

\subsection{Factors affecting FT classification agreement}

The FT-ESDR results determined from the $37 \mathrm{GHz} T_{\mathrm{b}}$ retrievals are sensitive to the predominant frozen or non-frozen status of the land surface within the sensor footprint. However, the actual FT pattern may be spatially complex due to variations in microclimate and land cover conditions that may not be adequately resolved by the coarse $(\sim 25 \mathrm{~km}$ resolution) satellite sensor footprint (Colliander et al., 2012; Du et al., 2015). The relative agreement between the FT-ESDR and in situ station-based FT results is therefore expected to be inversely proportional to land surface heterogeneity, including open water abundance and terrain complexity within the grid cell.

We investigated potential factors influencing FT classification agreement between the FT-ESDR and WMO SAT observations, including the open water fraction $\left(F_{\mathrm{w}}, \%\right)$ and elevation gradient $(\mathrm{m})$ within $25 \mathrm{~km}$ resolution EASE-Grid cells coinciding with the WMO validation stations. We also examined other factors potentially affecting FT classification agreement, including the level of per grid cell correspondence ( $r$ value) between the $T_{\mathrm{b}}$ retrievals and weighted ERAInterim daily SAT estimates used in determining the MSTA FT threshold (Eq. 2), and the mean annual number of classified transitional FT days defined from the AM and PM overpass $T_{\mathrm{b}}$ retrievals.

The mean annual FT classification agreement was analyzed for the selected year (2012) and found to be inversely proportional to $\mathrm{F}_{\mathrm{w}}$ (slope $=-0.25 \%, p<0.001$ ) as shown in Fig. 5a. These results confirm generally strong sensitivity of the $37 \mathrm{GHz} T_{\mathrm{b}}$ observations to the presence of surface water within the satellite footprint. The $T_{\mathrm{b}}$ sensitivity to $F_{\mathrm{w}}$ is consistent with large differences in dielectric properties, scattering albedo and microwave emissions between open water 
Table 2. Mean annual FT-ESDR PM overpass spatial agreement (\%) with WMO station-based FT metrics grouped into corresponding dominant IGBP land cover areas for 2012. Values represent mean and 1 standard deviation variability in relative spatial accuracy, while the number of weather stations used for FT accuracy assessment within each land cover category is also noted.

\begin{tabular}{lrrr}
\hline Land cover class* & PM overpass & AM overpass & Number of stations \\
\hline Open water & $77.5 \pm 18.3$ & $75.0 \pm 15.4$ & 536 \\
Evergreen needleleaf forest & $88.6 \pm 6.5$ & $84.5 \pm 6.3$ & 202 \\
Evergreen broadleaf forest & $98.6 \pm 4.3$ & $88.4 \pm 14.8$ & 38 \\
Deciduous needleleaf forest & $93.5 \pm 5.7$ & $89.3 \pm 4.7$ & 32 \\
Deciduous broadleaf forest & $96.2 \pm 3.1$ & $88.0 \pm 4.0$ & 84 \\
Mixed forest & $93.1 \pm 7.0$ & $86.7 \pm 6.7$ & 751 \\
Open shrubland & $95.8 \pm 5.9$ & $89.9 \pm 7.2$ & 345 \\
Woody savanna & $96.2 \pm 5.9$ & $92.1 \pm 5.9$ & 381 \\
Savanna & $99.1 \pm 2.6$ & $96.1 \pm 4.9$ & 19 \\
Grassland & $92.9 \pm 7.5$ & $87.7 \pm 6.9$ & 888 \\
Permanent wetland & $91.4 \pm 6.2$ & $86.4 \pm 4.9$ & 8 \\
Cropland & $94.9 \pm 5.7$ & $88.8 \pm 5.7$ & 1286 \\
Urban & $96.5 \pm 3.9$ & $89.5 \pm 4.6$ & 102 \\
Cropland/natural vegetation mosaic & $94.4 \pm 4.5$ & $87.2 \pm 4.4$ & 559 \\
Permanent snow/ice & $81.1 \pm 19.6$ & $83.1 \pm 21.3$ & 30 \\
Barren or sparsely vegetation & $94.3 \pm 6.5$ & $91.8 \pm 4.5$ & 82 \\
\hline
\end{tabular}

* Closed shrubland (CS) is excluded in this analysis because only a single CS station was identified.
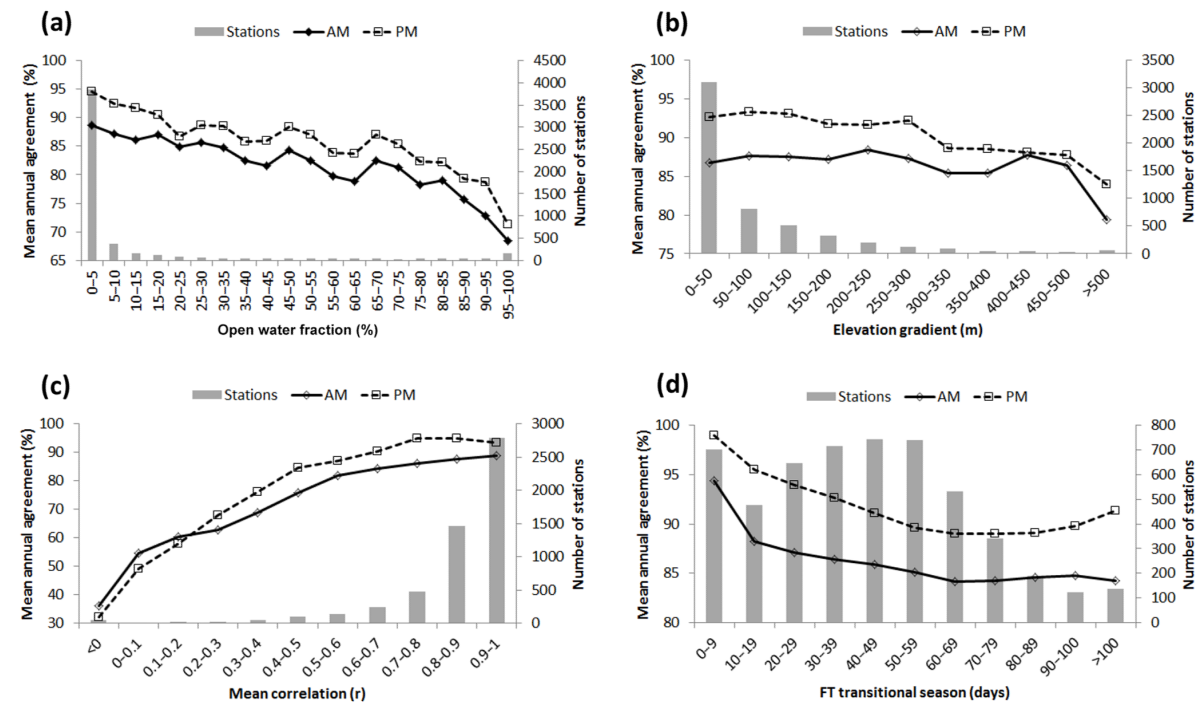

Figure 5. Dominant factors affecting AM and PM overpass FT classification agreement for individual grid cells, including (a) open water fraction within a grid cell $\left(F_{\mathrm{W}}, \%\right)$, (b) terrain elevation gradient $(\mathrm{m})$ within a cell, (c) correlation $(r$ value) of grid cell linear regression relationship between satellite $T_{\mathrm{b}}$ retrievals and weighted ERA-Interim SAT used in determining the MSTA FT threshold, and (d) the annual FT transitional season duration (days).

and adjacent land areas (Lemmetyinen et al., 2011; Rees et al., 2006). The $T_{\mathrm{b}}$ over lake ice may also be elevated relative to adjacent land areas during the frozen season (Green et al., 2012). These factors contribute to a general mismatch between in situ SAT observations that predominantly reflect local land surface conditions and satellite sensor $T_{\mathrm{b}}$ retrievals representing an integrated regional signal.
The FT classification agreement was inversely proportional to the elevation gradient (slope $=-0.01 \%, p<$ 0.001 ) within a grid cell (Fig. 5b), but with less apparent impact than $F_{\mathrm{w}}$. This negative relationship is consistent with generally greater heterogeneity in landscape dielectric properties and FT patterns, and associated microclimate variability in complex terrain, which may not be effectively delin- 


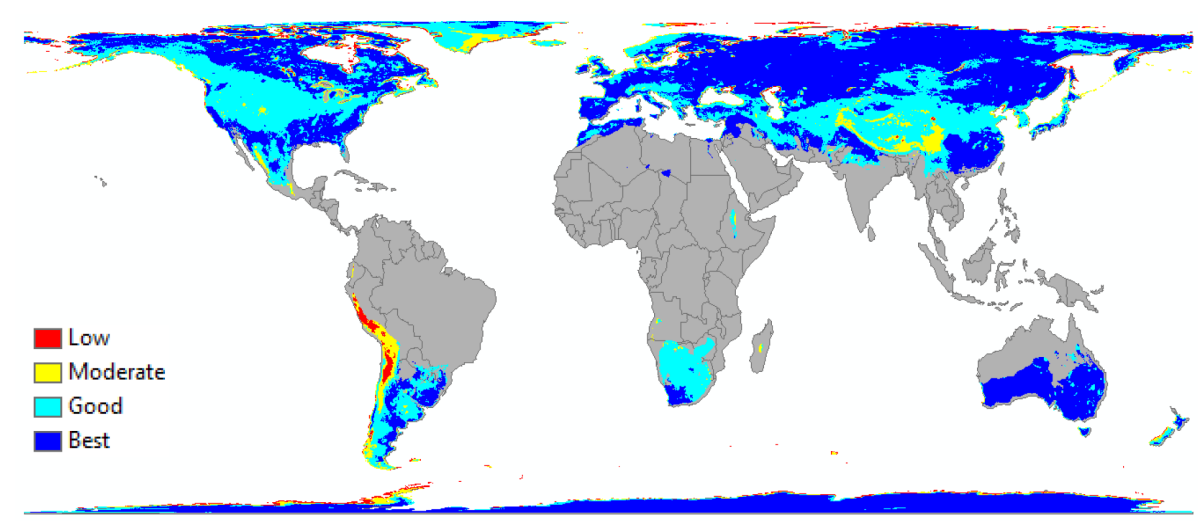

Figure 6. FT-ESDR annual quality assurance (QA) map for 2012, aggregated into low (estimated mean annual spatial classification agreement $<70 \%)$, moderate $(75-85 \%)$, good $(85-95 \%)$ and best $(>95 \%)$ relative quality categories. Land areas outside of the FT-ESDR domain are denoted by grey shading; grey shadings depict grid cells where the mean cold temperature constraint index (CCI) was less than 5 days year ${ }^{-1}$ from the 36 -year CCI record.

eated by the coarse $(25 \mathrm{~km})$ grid cell resolution (Du et al., 2015; Podest et al., 2014).

The FT classification agreement was directly proportional to the mean correlation between the satellite $T_{\mathrm{b}}$ retrievals and weighted ERA-Interim SAT used to define the MSTA FT threshold for each grid cell (slope $=34.3 \% ; p<0.001$; Fig. 5c). These results indicate that the FT classification is strongly sensitive to the reliability of estimated $T_{\mathrm{b}}$ threshold values, which may be influenced by uncertainty associated with use of reanalysis temperature data (Alexeev et al., 2012; Han et al., 2015; Screen et al., 2012). However, there were relatively few validation stations in cells with larger $F_{\mathrm{w}}$ cover, complex terrain, or lower $T_{\mathrm{b}}$ and SAT correlations, which may contribute uncertainties in assessing the impacts of these factors on FT classification accuracy.

The mean annual FT classification agreement was generally lower for grid cells with a longer FT transitional season (slope $=-0.1 \%, p<0.001$; Fig. 5d). These results are consistent with generally greater FT spatial heterogeneity and reduced classification agreement during seasonal transition periods (Fig. 4). These results are also consistent with previous studies documenting increased FT spatial complexity during seasonal transitions in spring and fall (Du et al., 2015; Naeimi et al., 2012; Rautiainen et al., 2014).

\subsection{FT quality assurance assessment}

The global QA map provides a discrete, grid-cell-wise indicator of relative FT-ESDR quality that accounts for potential negative impacts from $F_{\mathrm{w}}$ cover, terrain complexity, length of FT transitional season, and MSTA FT threshold uncertainty influencing mean annual classification accuracy. The resulting annual QA map for selected year 2012 is presented in Fig. 6 and shows regions of relative high to low quality. The QA values were stratified into a smaller set of discrete categories ranging from low (estimated mean annual FT classi- fication agreement $<70 \%$ ) to best $(>95 \%$ ) quality. Mean proportions of the four QA categories encompass $54.1 \%$ (best), $36.0 \%$ (good; $85-95 \%$ agreement), $6.6 \%$ (moderate; $75-85 \%$ agreement), and $3.3 \%$ (low) of the global FTESDR domain. The QA-based multivariate regressions were computed on an annual basis and explained more than half $(56.9 \pm 0.04$ [inter-annual SD] \%) of the observed global variation in mean annual FT classification agreement $\left(R^{2}\right)$ with the global WMO SAT validation stations over the 19792014 record.

The FT-ESDR contains additional quality control (QC) flags that identify other factors potentially affecting FT classification accuracy. The QC flags are spatially and temporally dynamic, and assigned on a per grid cell basis to denote missing satellite $T_{\mathrm{b}}$ records that are subsequently gap-filled through temporal interpolation of adjacent $T_{\mathrm{b}}$ retrievals prior to the FT classification. The QC flags also distinguish grid cells with large open water areas $\left(F_{\mathrm{w}}>0.20\right)$ and extreme elevation gradients $(>300 \mathrm{~m})$, and days with large precipitation events where FT classification accuracy is expected to be degraded. The inclusion of open-water-dominant grid cells allows for greater FT coverage, including extensive boreal and Arctic wetland areas that were excluded from previous FT-ESDR releases (Kim et al., 2011). Thus, daily FT estimates are still produced for grid cells with gap-filled $T_{\mathrm{b}}$ values, large $F_{\mathrm{w}}$ cover, extreme elevation gradients and large precipitation events, but with dynamic QC flags indicating potentially lower data quality (e.g. Fig. 5).

\subsection{FT-ESDR metrics comparison against independent cryosphere data}

\subsubsection{Lake and river ice phenology}

The FT-ESDR defined primary spring thaw date metric showed favorable correspondence $(r=0.79 ; p<0.01)$ with 


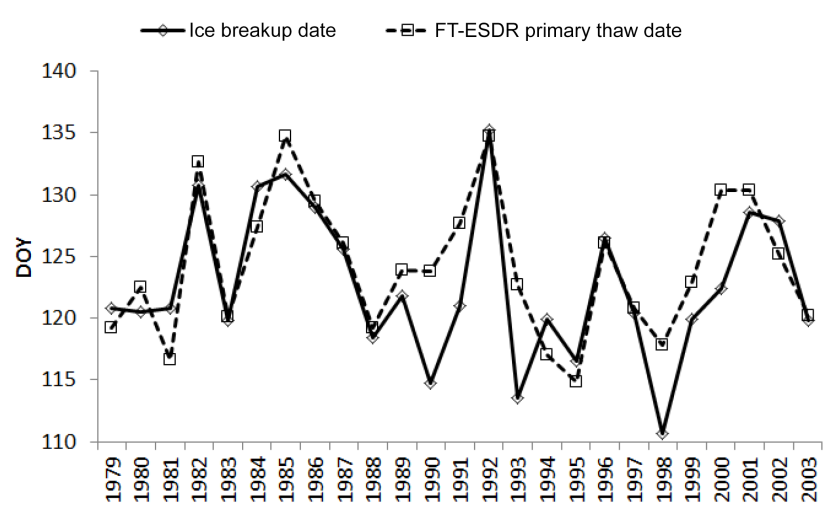

Figure 7. Correspondence between reported annual ice breakup dates for the Tanana River, Alaska $\left(64.56^{\circ} \mathrm{N}, 140.09^{\circ} \mathrm{W}\right)$, and FTESDR-derived primary spring thaw onset averaged within a $5 \times 5$ grid cell $(\sim 125 \mathrm{~km} \times 125 \mathrm{~km})$ window overlying the basin.

observed annual variations in spring ice breakup for the Tanana River $\left(64.56^{\circ} \mathrm{N}, 149.09^{\circ} \mathrm{W}\right)$ in interior Alaska over the 1979-2003 observation record (Fig. 7); here, in situ observations of river ice breakup timing (DOY) on the lower Tanana River are compared with the average FT-ESDRderived primary spring thaw date within a $5 \times 5$ grid cell domain centered over the site. Years with relatively early (late) river ice breakup in spring correspond with generally early (late) FT-ESDR defined spring thaw onset. These results are consistent with previous studies showing that the $37 \mathrm{GHz} T_{\mathrm{b}}$ retrievals and FT-ESDR results are sensitive to the onset of seasonal snowmelt within the basin, which increases runoff and the spring flood pulse that determine river ice breakup timing (Park et al., 2016b; Rawlins et al., 2005).

The FT-ESDR-based mean annual FS metric over lake dominated grid cells was directly proportional to collocated annual ice duration observations $(r=0.938 ; p<0.001)$ from the Global Lake and River Ice Phenology Database (1979-2013) as summarized in Fig. 8. The observed annual mean ice duration anomalies are obtained from $183 \pm 133.8$ [inter-annual SD] stations and locations representing northern $\left(\geq 36^{\circ} \mathrm{N}\right)$ land areas. These results indicate a direct frozen season impact on lake ice phenology, where years with a relatively longer (shorter) FS coincide with extended (reduced) ice duration. The FT-ESDR generally captures the observed annual lake ice variations despite lower apparent FT classification agreement for grid cells with greater $F_{\mathrm{w}}$ cover (Fig. 5). The FT-ESDR and lake ice observations both show significant trends $(p<0.001)$ toward shorter annual NFS and ice duration consistent with regional warming (Bekryaev et al., 2010), though the trends may also reflect a temporal decline in the number of reporting lake ice phenology stations. Generally, earlier FT-ESDR-derived primary spring thaw onset and a shorter frozen season relative to the in situ lake and river ice observations indicate earlier seasonal thawing of surrounding land areas, consistent with

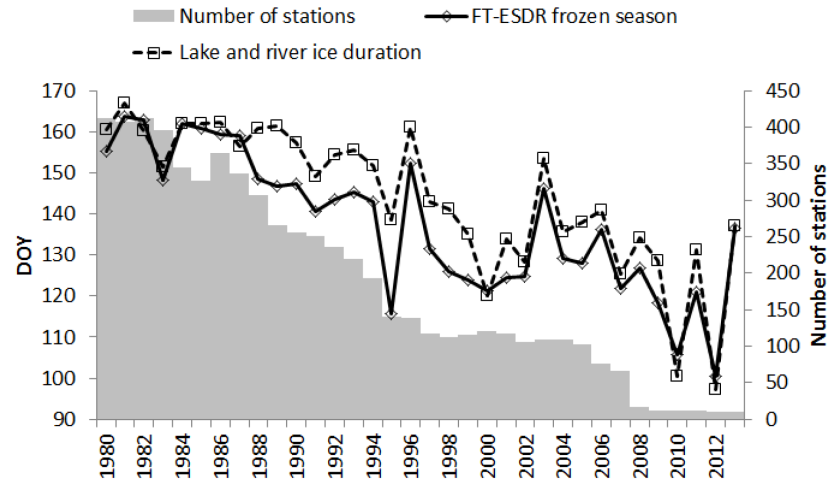

Figure 8. Correspondence between mean annual (1979-2013) lake ice duration observations from the Global Lake and River Ice Phenology Database (Benson and Magnuson, 2000), and collocated FTESDR-derived annual frozen season (frozen or transitional status) estimates.

snowmelt- and runoff-driven lake and river ice breakup (Park et al., 2016b). However, other factors influence lake and river ice phenology, including snow cover depth, ice thickness, water temperature and wind, which may contribute to differences between the satellite and in situ measurements.

\subsubsection{Greenland surface melt season}

The seasonal progression in the proportional area of surface melt (Mote, 2014) and FT-ESDR-derived non-frozen conditions over the Greenland ice sheet is shown for the selected year (2012) in Fig. 9a. Both daily records show similar seasonal patterns, but with the spring increase in FT-ESDRderived non-frozen conditions preceding the onset of surface melt. The FT-ESDR results also show a $4.3 \%$ larger non-frozen area relative to active melt areas; these discrepancies may reflect one or more factors, including different classification algorithms and environmental thresholds, and different sensitivities of the $37 \mathrm{GHz} \mathrm{V}$-pol and $\mathrm{H}-$ pol $T_{\mathrm{b}}$ retrievals used in the respective FT-ESDR and Greenland melt algorithms (Mote, 2014). The FT-ESDR-derived mean annual NFS over Greenland for 2012 is $50.1 \pm 29.1$ [spatialSD] days (Fig. 9b), with a shorter NFS for inland areas. The FT-ESDR also shows an extended NFS over the Greenland ice sheet in 1987, 1991, 2002 and 2012, relative to the long-term (1979-2014) satellite record (Fig. 9c). The extended NFS years are consistent with observed annual surface melt extremes documented from previous studies (Abdalati and Steffen, 2001; Hakkinen et al., 2014; Nghiem et al., 2012). The FT-ESDR annual mean NFS variability is directly proportional to annual mean surface melt area anomalies for Greenland over the 1979-2012 record $(r=0.535$; $p<0.001$; Fig. 9c). Both the FT-ESDR and Greenland surface melt data show generally increasing trends in NFS (1.7 days decade $\left.{ }^{-1} ; p=0.2\right)$ and annual melt area $(0.03$ million $\mathrm{km}^{2}$ decade $\left.{ }^{-1} ; p<0.001\right)$. These results coincide with 


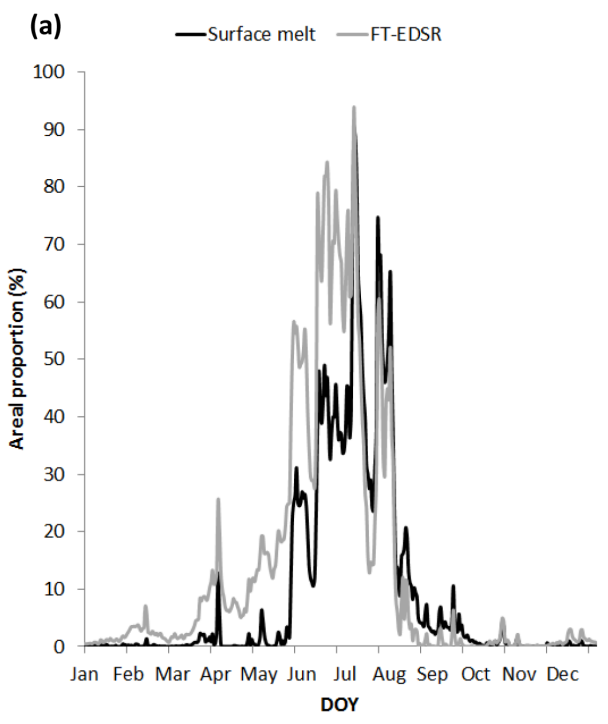

(b)
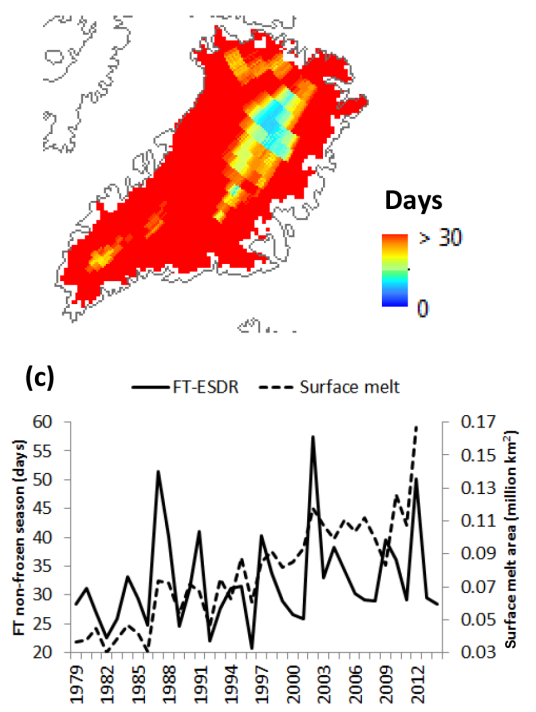

Figure 9. Seasonal progression in proportional area of surface melt (Mote, 2014) and FT-ESDR-derived non-frozen conditions over the Greenland ice sheet in 2012 (a). The spatial pattern of the FT-ESDR-derived annual non-frozen season (days) over the Greenland ice sheet is also shown (b). Annual variations in annual surface melt area and non-frozen season over the 36-year FT-ESDR record are also presented (c); these results document a general increase in the non-frozen season $\left(1.7\right.$ days decade $\left.{ }^{-1} ; p=0.2\right)$ that coincides with increasing surface melt $\left(0.03\right.$ million $\mathrm{km}^{2}$ decade $\left.^{-1} ; p<0.001\right)$ over Greenland and a $0.6^{\circ} \mathrm{Cdecade}^{-1}(p<0.01)$ regional SAT warming trend indicated from ERA-Interim reanalysis.

a $0.6{ }^{\circ} \mathrm{C}$ decade ${ }^{-1}(p<0.01)$ regional SAT warming trend indicated from the ERA-Interim reanalysis.

\section{Data availability}

The FT-ESDR is archived and distributed by the NASA Distributed Active Archive Center of the National Snow and Ice Data Center (NSIDC DAAC). The FT-ESDR can be accessed through the NSIDC online public data server (http: //nsidc.org/data/nsidc-0477).

\section{Summary and conclusions}

A new FT-ESDR was developed encompassing a larger global domain, longer (1979-2014) data record and refined classification algorithms relative to previous FT-ESDR versions (Kim et al., 2011). The FT-ESDR results show generally favorable agreement with daily FT estimates defined from global WMO weather station SAT measurements; the FT classification agreement was generally stronger for vegetated land areas (mean annual spatial accuracy from 77 to $97 \%$ for AM and PM overpasses) but was also favorable where other land cover classes were dominant within a grid cell, including urban (89.5-96.4\%), barren land (91.8-94.3\%), water bodies (75.0-77.5\%) and snowand ice-covered areas (81.1-83.1\%). The FT-ESDR results also showed general consistency with a broad set of other cryosphere datasets, including global lake and river ice phenology observations, and Greenland surface melt cycles.

The mean annual FT spatial classification accuracy relative to WMO weather station SAT measurements was approximately $90.3 \%$ (PM overpass) and $84.3 \%$ (AM overpass) over the global FT-ESDR domain and a 36-year satellite record. The apparent FT classification agreement was generally lower for grid cells with larger $F_{\mathrm{w}}$ cover, greater elevation complexity, and longer FT transitional periods. The FT classification agreement was also directly proportional to the correlation between the satellite $T_{\mathrm{b}}$ retrievals and corresponding ERA-Interim global reanalysis-based SAT values used for grid-cell-wise calibration of the MSTA FT thresholds. These results were used to define a relative FT-ESDR annual QA metric that explained more than half of the observed global variability in mean annual FT classification agreement. However, the grid-cell-to-point comparisons used for the QA assessment contained relatively few stations in cells with extreme terrain or $F_{\mathrm{w}}$ conditions, or with large disagreement between satellite and in situ FT dynamics, which lead to potential uncertainties in the FT classification assessment. Other factors potentially affecting FT classification accuracy were represented by dynamic QC flags assigned on a daily basis for each affected grid cell.

Overall, the expanded global domain and generally favorable FT-ESDR performance enables new potential science investigations encompassing wetlands, mountains and snow/ice-dominant land areas that were excluded from ear- 
lier FT-ESDR versions. The longer FT-ESDR also enables more refined assessments of global environmental changes that can distinguish transient weather extremes, landscape phenological shifts and periodic climate anomalies from longer-term climate trends extending over multiple decades.

Competing interests. The authors declare that they have no conflict of interest.

Acknowledgements. This work was conducted at the University of Montana under contract to NASA and supported under the NASA Making Earth System data records for Use in Research Environments (MEaSUREs) program (NNX14AB20A).

Edited by: K. Elger

Reviewed by: two anonymous referees

\section{References}

Abdalati, W. and Steffen, K.: Greenland ice sheet melt extent: 1979-1999, J. Geophys. Res., 106, 33983-33988, 2001.

Alexeev, V. A., Esau, I., Polyakov, I. V., Byam, S. J., and Sorokina, S.: Vertical structure of recent arctic warming from observed data and reanalysis products, Clim. Change, 111, 215-239, 2012.

Andre, C., Ottle, C., Royer, A., and Maignan, F.: Land surface temperature retrieval over circumpolar Arctic using SSM/I-SSMIS and MODIS data, Remote Sens. Environ., 162, 1-10, 2015.

Armstrong, R., Knowles, K., Brodzik, M., and Hardman, M. A.: DMSP SSM/I-SSMIS Pathfinder Daily EASE-Grid Brightness Temperatures, Version 2 [1987-2014], Boulder, Colorado USA, NASA DAAC at the National Snow and Ice Data Center, available at: http://nsidc.org/data/nsidc-0032.html (updated 2015), 1994.

Bekryaev, R. V., Polyakov, I. V., and Alexeev, V. A.: Role of polar amplification in long-term surface air temperature variations and 65 modern arctic warming, J. Climate, 23, 3888-3906, 2010.

Benson, B. and Magnuson, J.: Global Lake and River Ice Phenology Database, Boulder, Colorado, USA, National Snow and Ice Data Center, doi:10.7265/N5W66HP8 (updated 2012), 2000.

Brodzik, M. J. and Knowles, K. W.: EASE-Grid: A versatile set of equal area projections and grids in Discrete Global Grids, edited by: Goodchild, M., Nat. Center Geographic Inf. Anal., Santa Barbara, CA, 2002.

Buermann, W., Bikash, P. R., Jung, M., Burn, D. H., and Reichstein, M.: Earlier springs decrease peak summer productivity in North American boreal forest, Environ. Res. Lett., 8, 024027 , doi:10.1088/1748-9326/8/2/024027, 2013.

Chang, A. T. C., Foster, J. L., and Hall, D. K.: Satellite sensor estimates of northern hemisphere snow volume, Int. J. Remote Sens., 11, 167-171, 1990.

Colliander, A., McDonald, K. C., Zimmermann, R., Schroeder, R., Kimball, J. S., and Njoku, E. G.: Application of QuikSCAT backscatter to SMAP validation planning: Freeze/Thaw state over ALECTRA sites in Alaska from 2000 to 2007, IEEE T. Geosci. Remote, 50, 461-468, 2012.
Dee, D. P., Uppala, S. M., Simmons, A. J., Berrisford, P., Poli, P., Kobayashi, S., Andrae, U., Balmaseda, M. A., Balsamo, G., Bauer, P., Bechtold, P., Beljaars, A. C. M., van de Berg, I., Biblot, J., Bormann, N., Delsol, C., Dragani, R., Fuentes, M., Greer, A. J., Haimberger, L., Healy, S. B., Hersbach, H., Holm, E. V., Isaksen, L., Kallberg, P., Kohler, M., Matricardi, M., McNally, A. P., Mong-Sanz, B. M., Morcette, J.-J., Park, B.-K., Peubey, C., de Rosnay, P., Tavolato, C., Thepaut, J. N., and Vitart, F.: The ERAInterim reanalysis: Configuration and performance of the data assimilation system, Q. J. Roy. Meteorol. Soc., 137, 553-597, 2011.

Defourny, P., Kirches, G., Brockmann, C., Boettcher, M., Peters, M., Bontemps, S., Lamarche, C., Schlerf, M., and Santoro, M.: Land Cover CCI: Product User Guide Version 2, available at: http://maps.elie.ucl.ac.be/CCI/viewer/download/ ESACCI-LC-PUG-v2.5.pdf, 2016.

de Jong, R., Schaepman, M. E., Furrer, R., de Bruin, S., and Verburg, P. H.: Spatial relationship between climatologies and changes in global vegetation activity, Glob. Change Biol., 19, 1953-1964, 2013.

Dendoncker, N., Schmit, C., and Rounsevell, M.: Exploring spatial data uncertainties in land-use change scenarios, Int. J. Geogr. Inf. Sci., 22, 1013-1030, 2008.

Derksen, C., Walker, A., and Goodison, B.: Evaluation of passive microwave snow water equivalent retrievals across the boreal forest/tundra transition of western Canada, Remote Sens. Environ., 96, 315-327, 2005.

Du, J., Kimball, J. S., Azarderakhsh, M., Dunbar, R. S., Moghaddam, M., and McDonald, K. C.: Classification of Alaska spring thaw characteristics using L-band radar remote sensing, IEEE T. Geosci. Remote, 53, 542-556, 2015.

Ferraro, R. R., Weng, F., Grody, N. C., and Basist, A.: An eight-year (1987-1994) time series of rainfall, clouds, water vapor, snow cover, and sea ice derived from SSM/I measurements, B. Am. Meteorol. Soc., 77, 891-905, 1996.

Friedl, M. A., Sulla-Menashe, D., Tan, B., Schneider, A., Ramankutty, N., Sibley, A., and Huang, X.: MODIS Collection 5 global land cover: Algorithm refinements and characterization of new datasets, Remote Sens. Environ., 114, 168-182, 2010.

Frolking, S., McDonald, K. C., Kimball, J. S., Way, J. B., Zimmermann, R., and Running, S. W.: Using the space-borne NASA scatterometer (NSCAT) to determine the frozen and thawed seasons, J. Geophys. Res., 104, 27895-27907, 1999.

Green, J., Kongoli, C., Prakash, A., Sturm, M., Duguay, C., and Li, S.: Quantifying the relationships between lake fraction, snow water equivalent and snow depth, and microwave brightness temperatures in an arctic tundra landscape, Remote Sens. Environ., 127, 329-340, 2012.

Grody, N. C. and Basist, A. N.: Global Identification of snowcover using SSM/I measurements, T. Geosci. Remote Sens., 34, 237249, 1996.

Hakkinen, S., Hall, D. K., Shuman, C. A., Worthen, D. L., and DiGirolamo, N. E.: Greenland ice sheet melt from MODIS and associated atmospheric variability, Geophys. Res. Lett., 41, 16001607, 2014.

Han, M., Yang, K., Qun, J., Jin, R., Ma, Y., Wen, J., Chen, Y., Zhao, L., Zhu, L., and Tang, W.: An Algorithm based on the standard deviation of passive microwave brightness temperatures for 
monitoring soil surface freeze/thaw state on the Tibetan Plateau, IEEE T. Geosci. Remote, 53, 2775-2783, 2015.

Hasting, D. A., Dunbar, P. K., Elphingstone, G. M., Bootz, M., Murakami, H., Maruyama, H., Masaharu, H., Holland, P., Payne, J., Bryant, N. A., Logan, T. L., Muller, J.-P., Schreier, G., and MacDonald, J. S.: The global land one kilometer base elevation (GLOBE) digital elevation model, version 1.0, Nat. Ocean. Atmos. Admin., Nat. Geophys. Data Center, Boulder, CO, Digital data base on the World Wide Web and CD-ROMs, available at: http://www.ngdc.noaa.gov/mgg/toto/globe.html, 1999.

Holmes, T. R. H., De Jeu, R. A. M., Owe, M., and Dolman, A. J.: Land surface temperature from $\mathrm{Ka}$ band $(37 \mathrm{GHz})$ passive microwave observations, J. Geophys. Res., 114, D04113, doi:10.1029/2008JD010257, 2009.

Holmes, T. R. H., Crow, W. T., Yilmaz, M. T., Jackson, T. J., and Basara, J. B.: Enhancing model-based land surface temperature estimates using multiplatform microwave observations, J. Geophys. Res.-Atmos., 118, 577-591, 2013.

Howell, S. E. L., Brown, L. C., Kang, K., and Duguay, C. R.: Variability in ice phenology on Great Bear Lake and Great Salve lake, northwest territories, Canada, from SeaWinds/QuikSCAT: 20002006, Remote Sens. Environ., 113, 816-834, 2009.

Kanamitsu, M., Ebisuzaki, W., Woollen, J., Yang, S., Hnilo, J. J., Fiorino, M., and Potter, G. L.: NCEP-DOE AMIP-II reanalysis (R-2), B. Am. Meteorol. Soc., 83, 1631-1643, 2002.

Kenney, M. A. and Janetos, A. C.: National Climate Indicators System Report, National Climate Assessment and Development Advisory Committee, available at: http://www.globalchange.gov/sites/globalchange/files/

Pilot-Indicator-System-Report_final.pdf (last access: 11 May 2016), 2014.

Kim, Y., Kimball, J. S., McDonald, K. C., and Glassy, J.: Developing a global data record of daily landscape freeze/thaw status using satellite passive microwave remote sensing, IEEE T. Geosci. Remote, 49, 949-960, 2011.

Kim, Y., Kimball, J. S., Zhang, K., and McDonald, K. C.: Satellite detection of increasing northern hemisphere non-frozen seasons from 1979 to 2008: Implications for Regional Vegetation Growth, Remote Sens. Environ., 121, 472-487, 2012.

Kim, Y., Kimball, J. S., Zhang, K., Didan, K., Velicogna, I., and McDonald, K. C.: Attribution of divergent northern vegetation growth responses to lengthening non-frozen seasons using satellite optical-NIR and microwave remote sensing, Int. J. Remote Sens., 35, 3700-3721, doi:10.1080/01431161.2014.915595, 2014a.

Kim, Y., Kimball, J. S., Didan, K., and Henebry, G. M.: Responses of vegetation growth and productivity to spring climate indicators in the conterminous Unites States derived from satellite remote sensing data fusion, Agr. Forest Meteorol., 194, 132-143, 2014b.

Kim, Y., Kimball, J. S., Robinson, D. A., and Derksen, C.: New satellite climate data records indicate strong coupling between recent frozen season changes and snow cover over high northern latitudes, Environ. Res. Lett., 10, 084004, doi:10.1088/17489326/10/8/084004, 2015.

Kimball, J. S., McDonald, K. C., Keyser, A. R., Frolking, S., and Running, S. W.: Application of the NASA scatterometer (NSCAT) for determining the daily frozen and nonfrozen landscape of Alaska, Remote Sens. Environ., 75, 113-126, 2001.
Knowles, K.: EASE-Grid Land-Ocean-Coastline-Ice Masks Derived from Boston University MODIS/Terra Land Cover Data, NASA National Snow and Ice Data Center Distributed Active Archive Center, Boulder, Colorado USA, doi:10.5067/YR21Q0Q8IPR6, 2004.

Knowles, K., Njoku, E. G., Armstrong, R., and Brodzik, M.: Nimbus-7 SMMR Pathfinder Daily EASE-Grid Brightness Temperatures (1979-1987), NASA DAAC at the National Snow and Ice Data Center, Boulder, Colorado, USA, available at: http: //nsidc.org/data/nsidc-0071.html, 2000.

Lemmetyinen, J., Kontu, A., Karna, J., Vehvilainen, J., Takala, M., and Pulliainen, J.: Correcting of the influence through application of a microwave emission model, Remote Sens. Environ., 115, 3965-3706, 2011.

Mao, J., Fu, W., Shi, X., Ricciuto, D. M., Fisher, J. B., Dickinson, R. E., Wei, Y., Shem, W., Piao, S., Wang, K., Schwalm, C. R., Tian, H., Mu, M., Arain, A., Ciais, P., Cook, R., Dai, Y., Hayes, D., Hoffman, F. M., Huang, M., Huang, S., Huntzinger, D. N., Ito, A., Jain, A., King, A. W., Lei, H., Lu, C., Michalak, A. M., Parazoo, N., Peng, C., Peng, S., Poulter, B., Schaefer, K., Jafarov, E., Thornton, P. E., Wang, W., Zeng, N., Zeng, Z., Zhao, F., Zhu, Q., and Zhu, Z.: Disentangling climate and anthropogenic controls on global terrestrial evaporation trends, Environ. Res. Lett., 10, 094008, doi:10.1088/1748-9326/10/9/094008, 2015.

Matzler, C.: Passive microwave signatures of landscapes in Winter, Meteorol. Atmos. Phys., 54, 241-260, 1994.

Mote, T. L.: MEaSUREs Greenland Surface Melt Daily $25 \mathrm{~km}$ EASE-Grid 2.0, NASA National Snow and Ice Data Center Distributed Active Archive Center, Boulder, Colorado USA, doi:10.5067/MEASURES/CRYOSPHERE/nsidc-0533.001, 2014.

Naeimi, V., Paulik, C., Bartsch, A., Wagner, W., Kidd, R., Park, S., Elger, K., and Bioke, J.: ASCAT surface state flag (SSF): extracting information on surface freeze/thaw conditions from backscatter data using an empirical threshold-analysis algorithm, IEEE T. Geosci. Remote, 50, 2566-2582, 2012.

National Weather Services (NWS): Surface Observations, Federal Meteorological Handbook no. 1 (FCM-H1-1988), Dept. Commerce, Office Federal Coordinator, Washington, DC, 1988.

Nenana Ice Classic: Tanana River Ice Annual Breakup Dates, National Snow and Ice Data Center, Boulder, Colorado USA, available at: http://nsidc.org/data/nsidc-0064 (last access: 7 February 2017), 2011.

Nghiem, S. V., Hall, D. K., Mote, T. L., Tedesco, M., Albert, M. R., Keegan, K., Shuman, C. A., DiGirolamo, N. E., and Neumann, G.: The extreme melt across the Greenland ice sheet in 2012, Geophys. Res. Lett., 39, L20502, doi:10.1029/2012GL053611, 2012.

Owe, M. and Van De Griend, A. A.: On the relationship between thermodynamic surface temperature and high-frequency $(37 \mathrm{GHz})$ vertically polarized brightness temperature under semiarid conditions, Int. J. Remote Sens., 22, 3521-3532, 2001.

Owe, M., de Jeu, R., and Holmes, T.: Multisensor historical climatology of satellite-derived global land surface moisture, J. Geophys. Res., 113, F01002, doi:10.1029/2007JF000769, 2008.

Park, H., Kim, Y., and Kimball, J. S.: Widespread permafrost vulnerability and soil active layer increases over the high northern latitudes inferred from satellite remote sensing and pro- 
cess model assessments, Remote Sens. Environ., 175, 349-358, 2016a.

Park, H., Yoshikawa, Y., Oshima, K., Kim, Y., Ngo-Duc, T., Kimball, J. S., and Yang, D.: Quantification of warming climateinduced changes in terrestrial arctic river ice thickness and phenology, J. Climate, 29, 1733-1754, 2016 b.

Peterson, T. C.: Climate Change Indices, WMO Bulletin, 54, 83-86, 2005.

Podest, E., McDonald, K. C., and Kimball, J. S.: Multisensor microwave sensitivity to freeze/thaw dynamics across a complex boreal landscape, IEEE T. Geosci. Remote, 52, 6818-6828, 2014.

Prigent, C., Aires, F., and Rossow, W. B.: Land surface microwave emissivities over the globe for a decade, B. Am. Meteorol. Soc., 87, 1573-1584, 2006.

Rautiainen, K., Lemmetyinen, J., Schwank, M., Kontu, A., Menard, C. B., Matzler, C., Drusch, M., Wiesmann, A., Ikonen, J., and Pulliainen, J.: Detection of soil freezing from L-band passive microwave observations, Remote Sens. Environ., 147, 206-218, 2014.

Rawlins, M. A., McDonald, K. C., Frolking, S., Lammers, R. B., Fahnestock, M., Kimball, J. S., and Vorosmarty, C. J.: Remote sensing of snow thaw at the pan-Arctic scale using the SeaWinds scatterometer, J. Hydrology, 312, 294-311, 2005.

Rees, A., Derksen, C., English, M., Walker, A., and Duguay, C.: Uncertainty in snow mass retrievals from satellite passive microwave data in lake-rich high-latitude environments, Hydrol. Proc., 20, 1019-1022, 2006.

Screen, J. A, Deser, C., and Simmonds, I.: Local and remote controls on observed Arctic warming, Geophys. Res. Lett., 39, L10709, doi:10.1029/2012GL051598, 2012.
Ulaby, F. and Long, D. G.: Microwave Radar and Radiometric Remote Sensing, University of Michigan Press, Ann Arbor, Michigan, 2014.

Wang, X., Piao, S., Xu, X., Ciais, P., MacBean, N., Myneni, R. B., and $\mathrm{Li}, \mathrm{L} .:$ Has the advancing onset of spring vegetation greenup slowed down or changed abruptly over the last three decades? Global Ecol. Biogeogr., 24, 621-631, 2015.

Watanabe, M., Kadosaki, G., Kim, Y., Ishikawa, M., Kushida, K., Sawada, Y., Tadono, T., Fukuda, M., and Sato, M.: Analysis of the Sources of Variation in L-band backscatter from Terrains with permafrost, IEEE T. Geosci. Remote, 50, 44-54, 2011.

Zhang, K., Kimball, J. S., Kim, Y., and McDonald, K. C.: Changing freeze-thaw seasons in northern high latitudes and associated influences on evapotranspiration, Hydrol. Proc., 25, 4142-4151, 2011.

Zhang, S., Li, X., Ma, Y., Zhao, G., Li, L., Chen, J., Jiang, Z., and Huang, Y.: Interannual and seasonal variability in evapotranspiration and energy partitioning over the alpine riparian shrub Myricaria squamosal Desv. On Qinghai-Tibet Plateau, Cold Reg. Sci. Technol., 102, 8-20, 2014.

Zhao, M., Ramage, J., Semmens, K., and Obleitner, F.: Recent ice cap snowmelt in Russian High Arctic and anti-correlation with late summer sea ice extent, Environ. Res. Lett., 9, 045009, doi:10.1088/1748-9326/9/4/045009, 2014.

Zhu, Z., Piao, S., Myneni, R. B., Huang, M., Zeng, Z., Canadell, J. G., Ciais, P., Stich, S., Friedlingstein, P., Arneth, A., Cao, C., Cheng, L., Kato, E., Koven, C., Li, Y., Lian, X., Liu, Y., Liu, R., Mao, J., Pan, Y., Peng, S., Penuelas, J., Poulter, B., Pugh, T. A. M., Stocker, B. D., Viovy, N., Wang, X., Wang, Y., Xiao, Z., Yang, H., Zaehle, S., and Zeng, N.: Greening of the Earth and its drivers, Nat. Clim. Change, doi:10.1038/nclimate3004, 2016. 